\title{
Author Correction: Directed self-assembly of herbal small molecules into sustained release hydrogels for treating neural inflammation
}

\author{
Jun Zheng, Rong Fan, Huiqiong Wu, Honghui Yao, Yujie Yan, Jiamiao Liu, Lu Ran, Zhifang Sun, Lunzhao Yi,
} Li Dang, Pingping Gan, Piao Zheng, Tilong Yang, Yi Zhang (D), Tao Tang \& Yang Wang (D)

Correction to: Nature Communications https://doi.org/10.1038/s41467-019-09601-3, published online 8 April 2019.

The original version of this Article contained an error in Fig. 6b, in which the $48 \mathrm{~h}$ p-IkBa and NF-kB p65 panels looked identical. This has been corrected in both the PDF and HTML versions of the Article.

A correction to the supplementary information file has been made where the correct blots have replaced the incorrect bolts for Supplementary Fig. 13 for the 48 hour p-IkBa panel. These changes have been noted in the figure legend.

Published online: 27 July 2020

\footnotetext{
(c) (i) Open Access This article is licensed under a Creative Commons Attribution 4.0 International License, which permits use, sharing, adaptation, distribution and reproduction in any medium or format, as long as you give appropriate credit to the original author(s) and the source, provide a link to the Creative Commons license, and indicate if changes were made. The images or other third party material in this article are included in the article's Creative Commons license, unless indicated otherwise in a credit line to the material. If material is not included in the article's Creative Commons license and your intended use is not permitted by statutory regulation or exceeds the permitted use, you will need to obtain permission directly from the copyright holder. To view a copy of this license, visit http://creativecommons.org/licenses/by/4.0/.
}

(C) The Author(s) 2020 